
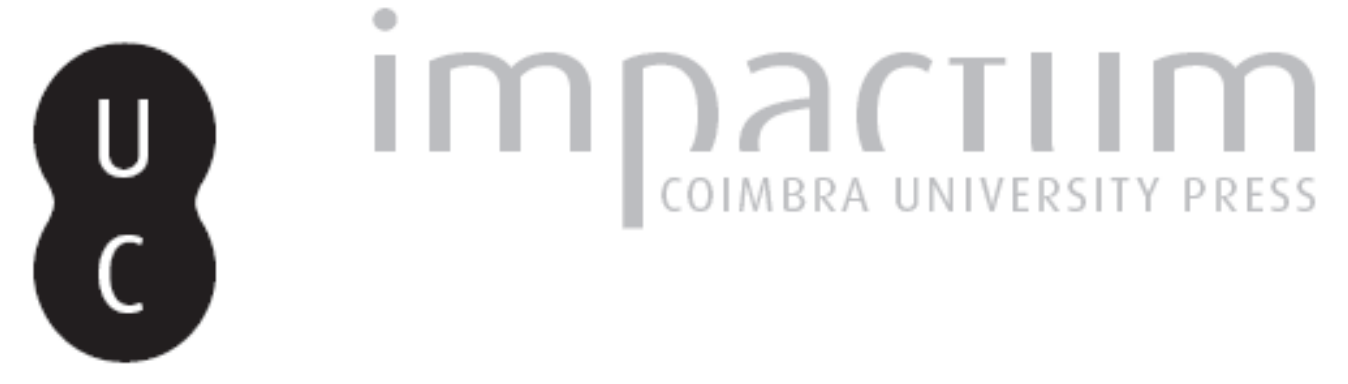

\title{
Evidencias de un nuevo taller cerámico del alfarero GES en Augusta Emerita
}

Autor(es): $\quad$ Bustamante-Álvarez, Macarena; Bejarano Osorio, Ana M.

Publicado por: Faculdade de Letras da Universidade de Coimbra

URL persistente:

URI:http://hdl.handle.net/10316.2/38798

DOI:

DOI:http://dx.doi.org/10.14195/1647-8657_53_5

Accessed : $\quad$ 26-Apr-2023 15:33:14

A navegação consulta e descarregamento dos títulos inseridos nas Bibliotecas Digitais UC Digitalis, UC Pombalina e UC Impactum, pressupõem a aceitação plena e sem reservas dos Termos e Condições de Uso destas Bibliotecas Digitais, disponíveis em https://digitalis.uc.pt/pt-pt/termos.

Conforme exposto nos referidos Termos e Condições de Uso, o descarregamento de títulos de acesso restrito requer uma licença válida de autorização devendo o utilizador aceder ao(s) documento(s) a partir de um endereço de IP da instituição detentora da supramencionada licença.

Ao utilizador é apenas permitido o descarregamento para uso pessoal, pelo que o emprego do(s) título(s) descarregado(s) para outro fim, designadamente comercial, carece de autorização do respetivo autor ou editor da obra.

Na medida em que todas as obras da UC Digitalis se encontram protegidas pelo Código do Direito de Autor e Direitos Conexos e demais legislação aplicável, toda a cópia, parcial ou total, deste documento, nos casos em que é legalmente admitida, deverá conter ou fazer-se acompanhar por este aviso.

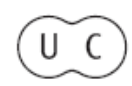


CONIMBRIGA

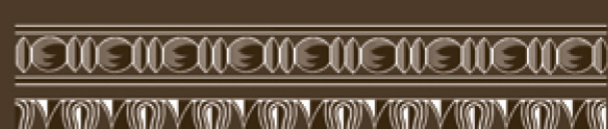

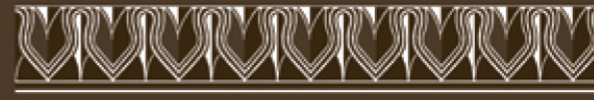

INSTITUTO DE ARQUEOLOGIA

VOLUME LIII • 2014

FACULDADE DE LETRAS 
Macarena Bustamante-Álvarez

Programa Juan de la Cierva / Universidad Autónoma de Madrid

macarena.bustamante@uam.es

Ana M. ${ }^{a}$ Bejarano Osorio

Consorcio Ciudad Monumental de Mérida

EVIDENCIAS DE UN NUEVO TALLER CERÁMICO

DEL ALFARERO GES EN AUGUSTA EMERITA

EVIDENCE OF A NEW CERAMIC POTTER'S WORKSHOP

OF GES IN AUGUSTA EMERITA

“Conimbriga" LIII (2014) p. 145-175

http://dx.doi.org/10.14195/1647-8657_53_5

ABSTRACT: We present the evidence of what we consider the dump of a figlina at the site of Augusta Emerita (Mérida, Spain). This plot is located in the current Duque de Sala, Street $\mathrm{n}^{\circ} 50$ corner Cesar Lozano Street. Urbanistically it is well positioned in the northwest quadrant of the city, on the side of one of the highest elevations, called Cerro del Calvario and close to the rivers of the Guadiana and Albarregas. The interest of this site is the production of lamps with the sigillum of one of the best known potters of the city -GES. Also we provide chronological and typological data in this article.

KEYWORDS: Augusta Emerita; pottery; figlina

Resumo: Apresentamos as evidências do que se considera ser o despejo de uma figlina em Emerita Augusta (Mérida, Espanha). O espaço localiza-se na atual rua Duque de Sala, . $^{\circ} 50$, com a esquina da rua Cesar Lozano. Urbanisticamente está bem posicionado no

Conimbriga, 53 (2014) 145-175 
quadrante noroeste da cidade, ao lado de uma das maiores elevações, o chamado Cerro del Calvario e perto dos rios Guadiana e Albarregas. O sítio corresponde à oficina de produção cerâmica, de lucernas e de queimadores com o sigillum de um dos oleiros romanos mais conhecidos da cidade -GES. Tecem-se ainda considerações de ordem cronológica e tipológica relativas ao achado.

PALAVRAS-CHAVE: Augusta Emerita; cerâmica; figlina 


\section{EVIDENCIAS DE UN NUEVO TALLER CERÁMICO DEL ALFARERO GES EN AUGUSTA EMERITA}

\section{Introducción}

Presentamos las evidencias de lo que consideramos un testar con desechos productivos de una figlina en el yacimiento de Augusta Emerita. Dicho solar se encuentra ubicado en la actual c/Duque de Sala, n. ${ }^{\circ} 50$ esquina c/César Lozano. Urbanísticamente se posiciona así en el cuadrante Noroeste de la ciudad, en la ladera de una de las elevaciones más altas, el denominado Cerro del Calvario y muy próximo a los cursos fluviales del Guadiana y el Albarregas. Recordemos que ésta es una de las zonas que más ampliamente han sido ocupadas desde época Calcolítica (FIg. 1) (BARRIENTos et alii 1997; JiMÉNEZ 2005).

La motivación de esta obra, vino de la mano de la construcción de una nueva vivienda en una de las zonas que más respetan la fisonomía tradicional del urbanismo moderno-contemporáneo de Mérida.

Durante el desarrollo de dicha intervención, entre los meses de agosto y septiembre del año 2006, se documentaron parcas estructuras que permitieron fijar una ocupación diacrónica constante desde los primeros tiempos de la colonia, alternándose estructuras industriales con espacios funerarios tardoantiguos. De todas estas fases, la que va a centrar nuestro trabajo es la más antigua donde, dentro de un depósito revestido de opus signinum apareció un conjunto de cerámicas fragmentadas y, en muchos casos, con fuertes trazas de termoalteración (bien deformadas o bien con colores oscuros) que junto con la reiteración de ciertas formas, nos ofrece indicios para pensar que estamos ante las postrimerías de un taller alfarero especializado.

Estos hallazgos nos permiten confirmar la instalación de un área artesanal dedicada a la producción de cerámica en esta zona hasta, al menos, fines del I d.C. momento en el cual se inicia la expansión de una necrópolis de incineración por toda la zona. Así mismo, la especia- 
lización del taller en la producción de lucernas y pebeteros, unido a la aparición de varios sellos del alfarero GES sobre algunas piezas defectuosas, nos permiten ubicar espacialmente el taller de este alfarero, uno de los más afamados del territorio emeritense.

\section{Contextualización espacial e histórica}

La superficie concreta en la que se ha intervenido corresponde a un área de 101'48 m2. La intervención efectuada ha alcanzado los niveles de roca natural en la totalidad del solar (FIG. 2). Directamente sobre él, se pudo documentar los primeros horizontes de uso, con un buzamiento Sur-Norte. La ocupación de la zona conocida como Cerro del Calvario, está atestiguada desde temprana época, más concretamente durante el Calcolítico (BARRIENTOS et alii 1997; JiMÉNEZ 2005), aun cuando la urbanización global del espacio correspondió con el período romano.

La delimitación de la ciudad en esta zona durante la etapa romana se pone de manifiesto por el registro de la muralla fundacional que, en la parte que nos ocupa, plantea serias dudas en su trazado ya que no ha sido documentada en ningún punto. Actualmente, en función de una intervención efectuada en el año 2006 se establece su desarrollo entre la c/ Prudencio y c/ Augusto confluyendo en la av. Fernández López (BEJARANO 2006: dep. doc. 8106). La muralla se ciñe al trazado natural del terreno y presenta una fuerte pendiente impuesta por la confluencia de los ríos Guadiana y Albarregas.

El solar se ubica en un espacio periférico extramuros de la ciudad de época romana. Esta zona ha sido objeto de numerosas intervenciones arqueológicas a lo largo de los últimos años. Refiriéndonos a la misma c/ Duque de Salas, nos remitimos a los números 12 y 63. Estas intervenciones exhumaron una secuencia ocupacional desde época romana, con un área funeraria donde se registran enterramientos de incineración y espacios indeterminados en los cuales se han identificado restos de estructuras murarias y canales. Recientemente, con motivo de unas zanjas efectuadas en el inicio de la calle, n. ${ }^{\circ}$ reg. 2575 (SÁnchez 2007: 417418 , fig. 10) se ha puesto de manifiesto la presencia de restos de muros y pavimentaciones de opus signinum.

En cercanía, ya que este solar está en la confluencia con la c/ César Lozano, nos encontramos una serie de intervenciones que, con los números de registro 5004, 6002 y 8103 (RoDríGUEZ 2015: e.p.), hacen 
referencia a un área funeraria de época romana y a la presencia de un alfar y vertedero en época contemporánea que nos permiten vislumbrar la cristalización funcional de este espacio.

Alejándonos de la zona de intervención, pero igualmente extramuros, nos centramos en los trabajos efectuados en el n. ${ }^{\circ} 44$ de la c/ Augusto (Palma 2004: 139-154). Allí aparecieron restos de un horno del s. I d.C., nuevamente un área funeraria fechada entre los s. II-III d.C., un hallazgo puntual de muros y cimentaciones del s. IV-V d.C. y un vertedero del s. VI d.C. Otra intervención en el n. ${ }^{\circ} 3$ de esta misma calle (SÁNCHEZ 1997: 128-134) permitió documentar una serie de enterramientos infantiles de inhumación datados entre los s. I-II d.C., con una fase posterior en la que nos encontramos con una estructura de opus caementicium vinculada con la muralla de época tardía.

En esta misma calle y en la confluencia con la c/ Ramón y Cajal, se excavó en el año 2006 un solar en el que se pudo documentar una secuencia que se inicia con una serie de estructuras de época altoimperial y posible carácter doméstico (no se descarta su utilidad industrial), a la que se le superpone tras una etapa de amortización datada en el bajoimperio, una secuencia constructiva de ámbito doméstico fechada en época visigoda (BEJARANo 2006: dep. doc. 8106).

Relacionado con la producción cerámica propiamente dicha, además del horno localizado en la c/Augusto y que ha sido asociado a la manufactura de latericios (PALMA 2004), existe la teoría de que hubiera en la zona un complejo productivo asociado a la producción de vajilla fina y lucernas. Esta área productiva, definida de antiguo como zona tren-Pancaliente (CALERO 1986: 93), ha sido perfilada en la actualidad como uno de los focos de producción de lucernas de la capital de la Lusitania (RodRíGuEZ 2002: 233). Esta ubicación, en una zona inmediata a la muralla, fue también la elegida para instalar el otro complejo productivo lucernario hasta el momento conocido en Mérida, la c/ Constantino (RodRíGuez 1996), confirmándose así la predisposición por ubicar estas oficinas en espacios extra-moenia pero muy cercanos a la misma.

Por consiguiente, la condición de suburbium de la zona viene evidenciada por la aparición de estructuras y espacios que son típicos de estos cinturones exteriores a los núcleos urbanos, es decir, zonas artesanales y necrópolis. 


\section{Desarrollo de la intervención}

\subsection{La ocupación contemporánea}

La intervención efectuada en el solar de la c/ Duque de Salas n. ${ }^{\circ} 50$, comenzó con la limpieza de un sondeo previo (n. ${ }^{\circ}$ reg. 2756) efectuado el año 2004 que posibilitó una autopsia directa de la estratigrafía con la que nos enfrentaríamos a posteriori.

La elevación natural que presenta esta zona y la afloración de la roca madre en una cota muy superior, han generado que la sedimentación se haya perdido en muchos puntos de ahí que las estructuras que hemos localizado aparezcan muy arrasadas, documentándose únicamente los niveles altoimperiales y tardorromanos.

Realizados los trabajos de demolición previos, se procedió a la limpieza de los niveles de escombros que cancelaban los suelos de época contemporánea. Visto el potencial de material y estructuras contemporáneas que ocupaban la totalidad de la superficie del solar, se procedió a desmantelar todos estos elementos con medios mecánicos así como a eliminar el correspondiente nivel de relleno que, de forma intencionada, se había vertido en la totalidad de la superficie delimitada, para elevar la cota de uso y dar base a las construcciones contemporáneas allí ubicadas.

\subsection{El área funeraria}

Una vez rebajado el sustrato de amortización contemporáneo se documentaron estructuras arqueológicas de carácter funerario que venían a confirmar la existencia de una amplia necrópolis, como ya nos venían advirtiendo las intervenciones de los solares adyacentes (FIG. 3 y 4). Al respecto, se ha documentado dos niveles de ocupación que se superponen y que nos hablan de una continuidad espacial cristalizada en dos etapas funerarias a las que podemos asociar una decena de tumbas entre ambos periodos.

Comenzando la descripción por la fase datada en el bajoimperio, se han documentado cinco enterramientos que siguen el ritual de la inhumación (A3, A10, A11, A12 y A15), acorde a la etapa en la que se incluyen. Estructuralmente, se depositan indistintamente en simples fosas, algunas delimitadas en su perímetro interno con materiales rea- 
provechados (A12) en cajas de ladrillos con cierta buena factura en su elaboración para la que se han empleado módulos semejantes (A10), o bien cajas en las que se ha optado por el material reutilizado (fragmentos de ladrillos, piedras, etc.) (A15). La orientación asignada a cada enterramiento varía desde la Noreste-Suroeste (A10), a la Oeste-Este (A15), o Sur-Norte (A3, A11, A12), direcciones impuestas en muchos casos por la falta de terreno libre, limitado por la etapa de ocupación precedente. Desconocemos los cierres de las distintas estructuras, a excepción de los túmulos de tierra en aquellas fosas simples excavadas en la roca.

En relación a la situación de los cuerpos, estos se colocaron en la tradicional posición decúbito supino. Se han podido identificar: un niño de corta edad (A15), tres varones y una mujer, todos ellos adultos. El niño se hacía acompañar de un plato (Smit Nolen 2c) depositado a la altura del hueso pélvico a la derecha, un anillo de bronce, una moneda de bronce (As de Claudio), una segunda moneda de bronce a los pies, y en la misma zona cuatro clavos de hierro; la mujer presentaba como depósito un ungüentario de vidrio (Caldera 71) a la altura izquierda del cráneo, una jarra, un cuenco en ARSW-A del tipo Hayes 15 (FIG. 4, nn. 1-3), un objeto de hierro que interpretamos como anclaje de gran tamaño y una barra de hierro que estaba inserta en la parte occipital izquierda del cráneo sobresaliendo de éste y colocado en posición invertida (la punta hacia fuera); por último, de los tres varones documentados, únicamente uno de ellos presentaba depósito material asociado, una escudilla (Smit Nolen 6b), una jarra (Smit Nolen 1c) y cinco cabezas redondeadas de clavos de hierro.

En relación al grupo de incineraciones documentadas y que corresponden a la primera fase asociada al área funeraria, son cuatro las tumbas registradas, algunas de ellas en precario estado, limitándose su identificación a la fosa y los escasos restos de carbones conservados en su interior (A8, ue.78). Solamente hay una incineración que se ha documentado completa, la (A5), fosa de planta rectangular excavada en la roca natural, en cuyo interior y amortizada por un sustrato de tierra de relleno, localizamos restos que componían el depósito funerario, una ollita biansada (Smit Nolen 1c), clavos de hierro, fragmentos cerámicos, una lucerna (Leibundgut XVII) y un cubilete de cerámica, junto a los restos de la cremación propiamente dicha, básicamente carbones y cenizas con escasísimos restos óseos humanos de un adulto calcinado. Una segunda incineración que aportó datos materiales (A 16), se lo- 
calizaba en perfil oriental del solar, por lo que su registro fue parcial. Se trataba de una fosa excavada en la roca natural, en cuyo interior y colmatado por un sustrato de tierra de relleno, aparecen los restos de una cremación, carbones en su mayor parte. Entre el material cerámico aparecía una tapadera así como una ollita de perfil tronconcónico (FIG. 3, n.os 2-3).

La cronología de estos materiales no remite a una ocupación que se inicia a mediados del s. II d.C. y continúa en el s. III d.C.

\subsection{Estructuras asociadas a la ocupación romano altoimperial (s. I d.C.)}

La época que va a centrar nuestra atención es la altoimperial momento en el que vamos a localizar las principales evidencias que ratifican la hipótesis de que estamos ante el testar de una figlina.

De este momento, se han documentado numerosas fosas realizadas sobre la roca madre que horadaban la totalidad de la superficie y que, en su mayoría, se colmataban por los detritos antiguos y modernos (FIG. 5). Apriorísticamente, se observa una organización espacial y morfológica de las fosas que nos hacen plantearnos una serie de hipótesis sobre su factura y funcionalidad y que avanzamos podría estar relacionada con la extracción de materia prima, quizás barros. Se destaca su morfología rectangular (caso de la ue 1 o 14) y oblonga más irregulares (como las ue 7, 8 o 13), todas ellas con perfil de embudo muy profundo y pronunciado y amortizadas en época tardía con importantes restos de vertidos, muchos ellos con fuertes trazas de termoalteración.

Así mismo, el complejo aparecía circundado de manera oblicua por una zanja rectangular de planta alargada y sección recta (ue 3) que se adentraba en profundidad hasta la roca madre y que contenía en su interior las evidencias de un canal abierto realizado en opus signinum con abombamiento cóncavo en su parte central y restos de una pared de ladrillos dispuestos en horizontal y trabados con una ligera lechada de mortero de cal apreciable a tramos en las solera de la fosa. Este canal, entra en contacto con otro en la esquina más occidental (ue 33) inserto en una fosa de sección rectangular excavada en la roca natural con una orientación Sureste-Noroeste, en cuyo interior registramos la presencia de una estructura realizada mediante ladrillos en horizontal trabados con una ligera capa de mortero de cal, algunos de ellos

Conimbriga, 53 (2014) 145-175 
vencidos hacia el interior. Del mismo, sólo hemos documentado la parte del lateral sur ya que se inserta en el perfil del corte. Este canal presenta una bifurcación (ue 52) que, con orientación Suroeste-Noreste y sección rectangular, aparece colmatado por un nivel de relleno (ue 53).

Asociado probablemente al canal, se ha recogido abundante material, que pasaremos a comentar en el siguiente apartado y amortizaba los restos de dos balsas cuadrangulares en opus signinum. De la primera, muy deteriorada (ue 15) hemos localizado los restos de la pared Este, con tendencia redondeada y acabada con un bocel semicircular que se prolonga por un suelo parcialmente desaparecido. La otra se presenta más desarrollada (A 4), como cubeta prácticamente cuadrada delimitada por cuatro muros muy irregulares de dioritas (aprox. 1'86 m, E-W y 1'87 m, N-S), revestidos por una fina capa de opus signinum. De la lectura de paramento de esta última, se observa la inclusión de un muro de cierre sobre cimentación de cantos rodados, que ubicaba el espacio interior al Sur, reduciendo su perímetro interno.

La cercana ubicación de ambas piletas que, incluso por prolongación de la más deteriorada entraría en contacto con la otra en una primera fase, nos permite lanzar la hipótesis de que en un primer momento ambas funcionaran de manera coetánea y en conexión. Al respecto, un posible complejo de decantación a dos alturas, como se saca en conclusión por la diferencia de cota de suelo, podría dar explicación a esta ordenación espacial en el complejo.

$\mathrm{Si}$ a esta estructura le unimos la existencia de fosas de extracción de materia prima por todo el solar de manera organizada y con perfiles muy concretos a modo de embudo, quizás para seguir las vetas plásticas que entendemos fueron las que motivaron este complejo, la relación de estas estructuras con los espacios alfareros documentados a escasos metros en la zona es plausible. A esto habría que unirle la aparición de canales que aportarían el recurso hídrico a la zona.

Además de las estructuras antes descritas y de la existencia de alfares en la zona de época romana -y también en momentos contemporáneos- hemos localizado un repertorio cerámico muy homogéneo y reiterativo, a lo que se le debe unir evidencias de sobreccoción y deformación en algunos ejemplares. Esto apoyaría la hipótesis de que estamos ante las descargas defectuosas de algunos hornos de la zona, vertidas directamente sobre las cubetas de opus signinum que ya habían dejado de funcionar en estos momentos. 


\section{Las cerámicas localizadas en el solar. Evidencias de un taller aso- ciado a GES}

La motivación principal de este estudio, era dar a conocer un conjunto de piezas cerámicas muy homogéneas tipológicamente y que presentaban ciertos rasgos de termoalteración. Las mismas fueron volcadas directamente sobre el depósito de opus signinum localizado en la intervención y perteneciente a la inicial ocupación del solar, la primera mitad del I d.C. La datación del vertido la establecemos en los últimos decenios del I d.C. momento en el cual la balsa ya está en desuso. Asimismo la aparición de algunas piezas en su composición, caso de paredes finas locales o formas comunes bien fechadas en otros contextos locales en dicha cronología es otro de los elementos usados para su datación. Finalmente para apoyar esta datación tenemos la instalación de una necrópolis de incineración con piezas del tipo Hayes 15 en ARSW-A que suponen el final del complejo productivo.

Como ya hemos comentado, se localizó una serie de estratos vertidos directamente sobre las dos piletas documentadas y que venimos asociando a la descarga de un taller cercano. Todas las piezas presentan dos tipos de pastas concretas. La primera de ellas, sería la típica de las paredes finas locales, es decir, muy caolinítica, depurada y cocida a altas temperaturas. Únicamente se perciben algunas inclusiones negras, grises y parduscas de granulometría muy fina que actúan como aglutinantes de dichas pastas. El segundo grupo, lo conformaría unas pastas más toscas, de coloración anaranjada con tonos parduscos y desgrasantes de granulometría media-alta que le confieren roturas muy irregulares.

Lo significativo de este conjunto es que el $37^{\prime} 5 \%$ de las formas diagnosticables son lucernas altoimperiales tipológicamente muy homogéneas, selladas algunas por el alfarero GES, mientras que el 32'5\% serían pebeteros de perfil muy estandarizado. El hecho de que las otras piezas documentadas sean ínfimas en número también nos hablaría de cargas específicas y de la especialización concreta de la estructura productiva adyacente.

En algunas piezas se observan trazas de termoalteración que, en ciertos casos, la deforman. Esto no responde, según nuestra hipótesis, a pautas de uso ya que, en el caso de las lucernas, la piquera queda exenta del ennegrecido. Creemos que esto debe de asociarse a fallos técnicos en el proceso de cocción de ahí que las mismas fueran tiradas. 


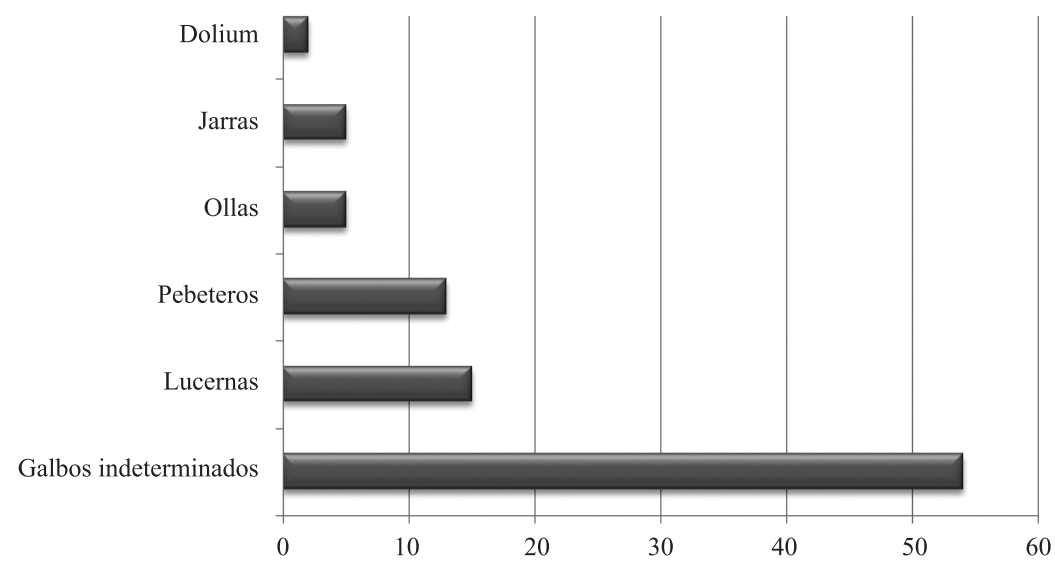

GrÁFICo 1 - Piezas localizadas en los niveles de vertido asociados a la descarga del horno

Si analizamos cuantitativamente los elementos localizados, predominan los galbos de cerámica común con aristas muy deterioradas que nos hablan de fracturas antiguas y que asociamos al vertido incontrolado de formas defectuosas en la zona. Le siguen las lucernas y los pebeteros, concluyendo con las ollas y jarras.

\section{Las lucernas}

Cuantitativamente las piezas más numerosas son las lucernas. Dos son los tipos predominantes en el conjunto, las Den. VG y las Den. VIIA. Todas ellas presentan pastas locales con acabados irisados asociables a la producción de paredes finas, hecho que parece ser la tónica habitual en la producción de lucernas durante el I d.C. (RoDRíGueZ 2002: 209).

Las más numerosas son las tipo Den. VG. (Fig. 5, n. ${ }^{\text {os }} 1-6,8$ y 10). Esta reiteración no nos debe extrañar pues estamos ante una de las formas más reiteradas en la producción emeritense, junto con las Den. IX (RoDRíGUEZ 2002: 212-213). Morfológicamente son unas piezas de reducidas dimensiones, entre los 5-9 $\mathrm{cm}$ de alto, por 6-7 $\mathrm{cm}$ de ancho, dando apariencia cuadrangular. La forma únicamente está aderezada por dos asideras laterales a modo de aletas que pueden estar más o me- 
nos grabadas así como decoradas. En este caso las aletas se acompañan con volutas en sus extremos que hacen acercarlas a la estética de algunos recipientes metálicos. El disco es liso presentando el orificio de alimentación muy centralizado. Esta zona se une a la piquera a partir de un estrecho canal que está flanqueado por un marco doble que acompaña al disco y acaba en la piquera.

Esta última característica es la clave de la transición entre las piezas de volutas y las de disco (Morillo 1999: 97). El pico de la pieza es de tendencia redondeada, exhibiendo, en algunas ocasiones, una terminación en punta más o menos acusada. La zona inferior presenta dos círculos concéntricos que delimitan la zona plana del fondo de la curvatura del infundibulum.

Las piezas localizadas en este conjunto, además de por sus pastas, presentan dos características que las diferencian de otras foráneas (como las presentadas por Casas y Soler 2002: E.675 en adelante) y que serían las que nos permiten hablar de las mismas como producciones locales:

A. - la unión entre la piquera y el disco se produce de manera continuada. Esto genera picos muy cortos que dan la sensación de ser pellizcos practicados en un extremo del disco. Las producciones oriundas de otras regiones presentan picos más avanzados y estilizados.

B. - las asas se presentan muy pegadas al disco frente al aspecto avanzado que se observa en otros ejemplares. Así mismo, de manera muy puntual, algunas de estas piezas presentan, en la misma unión entre su asa y el disco, unas incisiones circulares a caña.

Bajo nuestro punto de vista uno de elementos más interesantes de este estudio es que podamos otorgar una cronología a este tipo de lucernas, debido a su concentración a fines del I d.C. Genéricamente para éstas se ha propuesto una amplia datación desde que se definiera como de la primera mitad del I d.C. en los contexto de Cartago (Deneauve 1969: 31) o de Haltern (SzentLeleky 1969: 55). Tras ello han sido muchos los autores que han aportado una cronología más o menos dilatada a lo largo del siglo I d.C. (para ver una síntesis de ello RodríGUEZ 2002: 30-31). Para el noroeste peninsular su datación se focaliza en el segundo y tercer cuarto del I d.C. (MoriLlo 1999: 97). Para Mérida su amplia producción hace que la residualidad sea intensa hasta bien entra- 
do el siglo V-VI d.C. momento en el que las piezas siguen apareciendo pero con características tipológicas y pastas claramente altoimperiales (Palma 1998: lám. 15).

El problema cronológico que nos encontramos es ver qué correlación existe entre la cronología aportada por las piezas procedentes de otros talleres y las piezas emeritenses que centran nuestro estudio. Según los datos estratigráficos conocidos, las piezas Den. VG locales son producidas en momentos posteriores a los reinados de ClaudioNerón, tal y como se saca de conclusión al ver su ausencia en los contextos productivos de esta época, como en los vertederos de la c/ Constantino (RodRíGuez 1996: 66). Recordando ese estudio, en dicho enclave no aparecían las piezas prototípicas sino un híbrido primigenio sin los rasgos definidos que antes hemos esbozado.

Su aparición en contextos de consumo de fines del I d.C. en la capital de la Lusitania es continua. Un claro ejemplo lo localizamos en el puticulum del Cuartel de Hernán Cortés (HiDALGO et alii 2012). En él se presentan las características que determinamos como locales. Otros contextos, fuera de la capital de la Lusitania, como en el depósito de las lucernas de Castro Verde, datado a fines del I d.C. confirman, de nuevo, esta cronología (MaIA y MaIA 1997: 19 y 34-35). Por consiguiente, sin hacer valoraciones aplicables a otros talleres, apostamos que la producción y consumo de este tipo formal en Mérida se centre en el último tercio del I d.C. con unas características que le diferencian formalmente de las foráneas.

Junto a estas formas, minoritariamente, en el conjunto aparecen lucernas del tipo Den. VIIa (Fig. 5, n. ${ }^{\text {os }} 7$ y 9-10). Tipológicamente éstas quedan incluidas dentro de las lucernas de pica redondeada, presentan morfología oval con piquera a modo de apéndice circular con leve escalón que le separa del gran círculo del disco. Estas piezas presentan reducidas dimensiones.

Aunque puede aparecer decorada, la mayor parte de las veces se presenta lisa con espacio delimitado por tres o cuatro molduras simples que anulan al margo. La cronología de fines del I d.C. por la que apostamos viene también apoyada por la aparición de algunos ejemplares en suelo pompeyano (BISI 1977: 91).

Uno de los elementos más interesantes es la presencia de un sigillum en el que se lee GES en la parte trasera de una de las Den. VG y en una Den. VIIa (FIG. 5, n. ${ }^{\circ} 4$ y 7 respectivamente) realizado a mano alzada precocción, hecho normal en su producción (RoDRíGUEZ 2002: 
228). A este sello siempre se le ha supuesto un origen emeritense o de un entorno muy cercano. En este sentido Balil (1968: 8) desde un inicio apuntó bien a la capital de la Lusitania o bien en Villafranca, asimilada a la mansio de Perceiana. A día de hoy no se niega su carácter emeritense gracias a los hallazgos de la c/Oviedo (RoDRíGUEZ 2002: 162-163). Hasta el momento los estudios desarrollados en la capital de la Lusitania hablaban de una producción focalizada desde mediados del II d.C. hasta inicios del III d.C. con una evolución de grafía así como de representación (RoDRíGUEZ 2002: 163). En alguno de los ejemplares Den. VG de Mérida y su territorio, se han localizado sigilla asociados a ellos. El caso del depósito de Castro Verde es ejemplificador con cuatro ejemplares de Gavi(inia) (MaIA y MAIA 1997: 34-35). En Mérida se han localizado tres marcas incisas anepígrafas -tridente, tabas y aspa- (RodRíGUEZ 2002: 31) así como seis epigráficas -MPCR, VB, $L F O$ y $C L$ - (Rodríguez 2002: 32). A este elenco le debemos unir una $\mathrm{X}$ excisa, realizada a molde (en curso de estudio por una de las firmantes). Esta marca, en lo que se refiere a la gestación de estas piezas, es una innovación hasta el momento no documentada en las figlinae emeritenses.

\section{Los pebeteros}

Junto con la producción de lucernas, la aparición de pebeteros es casi pareja en número (FIG. 6). Al igual que ocurría con los tipos antes valorados aparecen algunos ejemplares deformados pero no termoalterados en su zona central hecho que sería lo normal en un contexto de consumo (FIg. 7). Esto vendría a indicar que estamos ante un defecto de producción y no una deformación generada por praxis.

Si de algo podemos caracterizar estas piezas es por la inmensa variedad, sobre todo en lo concerniente al borde así como a su decoración. Genéricamente estamos ante una copa amplia con pie elevado y hueco. El borde se presenta bífido al exterior siendo la diferenciación más acusada entre los ejemplares, la mayor o menor separación del labio inferior con respecto al cuerpo. Ante esto hemos podido diferenciar hasta tres tipos de borde (FIG. 8).

- Borde continuo: es decir aquel que no presenta diferencia con respecto a la pared. La parte inferior del mismo suele presentarse más gruesa, mientras que la superior es más fina y puede

Conimbriga, 53 (2014) 145-175 
tener un desarrollo más vertical. Esta continuidad también se aprecia en el interior del borde que acaba de manera simple y redondeada. A este grupo pueden adscribirse las piezas documentadas en el testar de la c/Constantino (Alvarado y Molano 1995: 292-293)

- Borde diferenciado y con tendencia caída: es decir, el labio inferior está exento del borde y además presenta una fuerte tendencia hacia abajo. A diferencia del tipo anterior, en el interior aparece un fuerte escalón que podría dar incluso pie a que se fuera el tope de una tapadera.

- Borde diferenciado con tendencia recta: es decir, el labio inferior está exento con una tendencia recta. Al igual que el tipo anterior posee en el interior un leve escalón.

En lo que respecta al pie es bastante simple a modo de base alta, hueca y con forma de disco en la parte exterior. La unión entre el cuerpo y el pie es simple a modo de cazoleta hemisférica donde depositar el producto a quemar.

Pero si de algo podemos caracterizar de innovador en esta producción es la decoración que presenta el borde (FIG. 9, n. ${ }^{\text {os }} 1-7$ y 10, n. ${ }^{\text {os }} 2-3$ y 6-9). En todos los ejemplares documentados el borde aparece doblemente decorado -en la parte superior e inferior- y previa a la cocción. La técnica es la misma, a partir de un instrumento que va extrayendo barro generando así una cenefa en onda tanto en la zona inferior como en la superior del borde bífido. En ocasiones se adereza con una línea incisa central. El hecho de que estemos ante una técnica realizada a mano alzada genera que cada creación sea única y así lo observamos en el conjunto de piezas localizadas las cuales presentan distintas incisiones en su decoración.

Este hallazgo viene a suponer la confirmación de los datos aportados por el vertedero de la c/ Constantino, donde ya se percibió una posible producción local pero con escaso impacto. El número de piezas ahora documentadas es mayor y ponen sobre la mesa la especialización tipológica de algunos de los talleres cerámicos de manera zonal. Para Mérida ya se había localizado otros ejemplares en contextos tanto de consumo como de producción de fines del I d.C. (Bustamante-Álvarez 2012: 427).

A falta de un estudio espacial y de distribución de estas piezas por todo el territorio emeritense, creemos que mayoritariamente su uso 
se restringiría a ambientes de votivos, hecho que no es óbice para que puntualmente se hiciera un uso doméstico de ellos.

Recordemos que la producción de pebeteros y lucernas en un mismo espacio productivo no es un hecho nuevo en la capital de la Lusitania. Claro ejemplo de lo indicado lo tenemos en los vertederos localizados en la c/ Constantino (Rodríguez 1996; Alvarado y Molano 1995) donde la producción de cerámica común se mezcla con las paredes finas, las lucernas y las terracotas. Al igual que en dicho vertedero tenemos la convivencia en un mismo estrato de todas estas categorías cerámicas. La similitud con este espacio también se observa en la propia ubicación del taller, a las afueras de la ciudad pero en el cinturón más cercano a la muralla. Esto quizás nos indicaría que la polución generada por esta producción no alcanzaría los niveles de otras de mayor envergadura, pongamos como ejemplo la gestación de ánforas posicionadas en la zona sur (ALBA y MÉNDEZ 2005: 389-390, fig. 34 y 35) o en la otra orilla del río Anas (Bustamante-Álvarez y Heras 2013).

\section{Otros tipos comunes}

Junto al grueso de las piezas, es decir, las lucernas y los pebeteros, en los mismos contextos de vertidos se han localizado algunos fragmentos de cerámicas comunes y paredes finas. Las escasas piezas documentadas no nos permiten abrir una línea de investigación más profunda sobre las mismas. A pesar de ello, el hecho que se hayan documentado en los mismos contextos de aparición que las otras nos permiten lanzar la hipótesis de que quizás estemos ante tipos y formas también producidas en el complejo pero no forzosamente en los mismos tiempos.

Al respecto tenemos un borde vuelto de olla así como un fondo plano que podría corresponder a un mismo tipo (Fig. 9, no. ${ }^{\text {os }}$ 8-9).Así mismo se ha localizado un ejemplar casi completo de olla biansada con decoración burilada central del tipo Emeritense 10, las cuales son típicas de fines del I d.C. (Fig. 10, n. ${ }^{\circ}$ 10) (Bustamante-Álvarez 2012: 416; Fig. 12). También debemos indicar la presencia de un borde de forma 633 en paredes finas locales con decoración burilada en su parte superior la cual tiene una presencia dilatada en el tiempo durante todo el I d.C. (Fig. 10, n. ${ }^{\circ}$ 1) (Martín y RodríGuez 2008: 388). 


\section{Conclusiones}

La intervención efectuada ha permitido conocer la evolución de un área que, en época romana, estaba extramuros, no obstante cercana a la muralla. A día de hoy, parecía indudable el carácter funerario de esta zona, por su ubicación periférica, confirmado por los datos extraídos en los procesos de excavación de solares cercanos.

No obstante, la secuencia registrada resulta un tanto más compleja ya que apreciamos la existencia de estructuras de carácter hidráulico que ocupaban el solar previo a la configuración del espacio como zona funeraria.

Comenzando con la primera fase de uso, hemos de referirnos a un canal que, con orientación Sur-Norte, atravesaba la totalidad del solar. Del citado canal nos restan escasos vestigios aunque los suficientes como para reconocer una estructura de ladrillos y una solera de pavimento impermeabilizante. Desconocemos si dispondría de cubierta o no. Vinculado al canal encontramos un depósito con paredes interiores, hastadonde la roca comenzaba a aparecer, revocado de una capa de opus signinum, igualmente con una función impermeabilizante. El punto de conexión entre ambos elementos se desconoce. En una etapa posterior, se aprecia una remodelación de estas estructuras, la primera de ellas en un momento en que el canal estaba aún en uso, consistente en el añadido de un nuevo canal, en este caso bifurcado, estando el principal construido con la misma técnica que el anterior mientras que el segundo sería de factura pobre, probablemente una simple abertura excavada en roca natural. Junto a este depósito aparecieron vestigios de otro, con el cual posiblemente formó una estructura de decantación a dos alturas como sacamos de conclusión por la ligera diferenciación de cotas.

De toda esta red de conducciones y depósito, desconocemos donde tendría su punto de arranque y su punto de salida. Únicamente apreciamos una clara pendiente en dirección Norte hacia la zona de la cuenca del Albarregas. Con toda probabilidad se trataría de canales destinados al aporte de aguas limpias y el depósito funcionaría como tal. La falta de relación con otros elementos, salvo lo hallado en el n. ${ }^{\circ} 63$ de la c/ Duque de Salas, donde se identificaron restos de estructuras murarias -depósito- y canales, nos impide definir el carácter doméstico o industrial de estas estructuras. 
Abandonados canales y depósito, asistimos a una colmatación de ambos y en el caso del depósito a una compartimentación de su espacio interior con la adicción de un muro que lo atraviesa. A destacar cómo dentro de los niveles de amortización de una estructura muraria de funcionalidad indeterminada, nos encontramos con una gran acumulación de pebeteros de cerámica común así como lucernas de aletas de temprana cronología que se adscriben a un único taller, el alfarero GES. Estas lucernas presentan como característica el hecho de estar defectuosas al igual que los fragmentos reconocidos de pebeteros que corresponden a este mismo taller. Su morfología, por comparativa con otros contextos productivos y de consumo, nos permite hablar de un vertido de fines del I d.C. A esto hay que añadirle la inclusión de otras piezas de paredes finas así como comunes, caso de ollas monoansadas buriladas, que también apoyarían esta cronología.

La reiteración de piezas de similar morfología, la aparición de trazas de quemado y la ubicación de estructuras de termoalteración en un radio cercano, apuntan a un complejo productivo en esas zona que vendría a apoyar la hipótesis de un área productiva en la zona de "Pancaliente", lugar que se ubica en la ladera oeste del Calvario (RoDRíGUEZ 2002: 230-235).

En el nivel de relleno se excavó una fosa destinada a un enterramiento de incineración que corta en parte los muros en alzado del depósito. Así mismo, en el interior del citado depósito y en los rellenos de colmatación de éste, se realiza una fosa indeterminada, y se excava el espacio destinado a una inhumación que ya formaría parte del uso de la zona como área funeraria. Adscrito a este momento encontramos varios enterramientos tanto de incineración como de inhumación. En el caso de las sepulturas de incineración, podemos hablar tanto de $u s$ trinum individual como de busta, todos en fosa simple. En el caso de las inhumaciones, se trata de fosas simples, con o sin delimitación de sus perímetros, fechada en época Julio-Claudia y una única caja de ladrillos. Se han hallado objetos que componen el depósito funerario y que nos otorgan en la mayor parte de los casos reconocidos cronologías de mediados-finales del s. I d.C. (A5). Probablemente, todas aquellas fosas que hallamos en el solar y que aparecen expoliadas y colmatadas por rellenos contemporáneos, formaran parte en su día de enterramientos y este dato nos lo confirmaría la existencia de la (A13), sepultura de incineración de la que nos han dejado los restos de la cremación así como el depósito funerario en la oquedad central. De incineración es 
igualmente la sepultura (A16) que presenta una datación más tardía, cifrada en el s. IV d.C.

El uso del espacio como área funeraria podemos sumarlo a los restos que han aparecido en otros puntos cercanos. Así, en la c/ César Lozano, (n. ${ }^{\circ}$ reg. 8103) hallamos enterramientos de inhumación que non obstante cabe fecharlos en época bajoimperial, alejados de la segunda centuria en que datamos las sepulturas asociadas a nuestro solar.

No obstante en la propia c/ Duque de Salas constatamos enterramientos de incineración altoimperiales y ya más alejados, en la c/ Augusto es donde únicamente a día de hoy hallamos enterramientos con una datación que se cifra entre los s. II-III d.C. (PALMA 2004: 139154) y en el n. ${ }^{\circ} 3$ de esta misma calle (SÁNCHEZ 1997: 128-134) donde se localizaron sendos enterramientos infantiles de inhumación datados entre los s. I-II d.C. Pocos datos tenemos de etapas posteriores salvo la fase de abandono del solar que se registra con la aparición de un sustrato casi uniforme de relleno. Este nivel de amortización definitiva del espacio se vio horadado por las obras posteriores que datamos en el s. XX como consecuencia de la construcción del hábitat contemporáneo.

A esta fase edilicia con toda probabilidad debamos de vincular el expolio de aquellas fosas, actualmente visibles, que asociamos a enterramientos de época romana. Así mismo, también debemos de situar en este período el expolio de los canales para la obtención de su material constructivo testimonio de este proceso es la ausencia total de restos asociados a la construcción de la estructura principal.

De igual modo, esta ubicación norteña en la ciudad confirma la hipótesis que planteamos hace ya varios años de un cambio espacial del mapa artesanal emeritense a lo largo del siglo I d.C. a medida que se iba tomando conciencia de la necesidad de poner orden a la polución gestada.

\section{BIBLIOGRAFÍA}

Alba Calzado, Miguel y Méndez Grande, Guadalupe (2005) - Evidencias de industria paleolítica y de un alfar emeritense en Augusta Emerita. Intervención arqueológica realizada entre la prolongación de la calle Anas y el final de la Avenida Lusitania, Mérida. Excav. Arqueol. 8 2002, p. 375-411.

Alvarado, Manuel y Molano, Juana (1995) - Aportaciones al conocimiento de las cerámicas comunes altoimperiales en Augusta Emerita: el vertedero de la calle Constantino. In Aquilué, X. y M. Roca, M. (eds.), Ceràmica comuna romana 
d'època altoimperial a la Península Ibèrica. Estat de la qüestió, Monografies Emporitanes VIII, Barcelona, p. 281-297.

Barrientos, Teresa, Jiménez Ávila, Javier y Montalvo, Ana (1997) - Nuevos hallazgos prehistóricos en el casco urbano de Mérida. Mérida. Excav. Arqueol. 3, p. 265-299.

Bejarano Osorio, A.M. (2006): Secuencia ocupacional de una parcela en la zona norte de Augusta Emerita. Intervención arqueológica realizada en el solar de la Augusto, c/ Ramón y Cajal.

Bissi, A. M. (1977) - Le lucerne fittili dei nuovi scavi di Ercolano, L'instrumentum domesticum di Ercolano e Pompei nella prima etá imperiale, Quaderni di Cultura Materiale 1, Roma.

Bustamante-Álvarez, Macarena (2012) - Las cerámicas comunes altoimperiales de Augusta Emerita. In Bernal, D. y Ribera, A. Las cerámicas hispanorromanas II. Las producciones regionales, Cádiz, p. 407-432.

Bustamante-Álvarez, Macarena y Heras, Francisco Javier (2013) - Producción anfórica en Augusta Emerita (Mérida, Badajoz) y los nuevos hallazgos del solar de la Escuela de Hostelería. In Bernal, D., Juan, L. C., Bustamante, M., Díaz, J. J. y Sáez, A. M. (eds.), Hornos, talleres y focos de producción alfarera en Hispania, I Congreso Internacional de la SECAH Ex officina hispana, (Cádiz) 3-4 de marzo de 2011, Monografias de la Sociedad de Estudios de la Cerámica Antigua en Hispania I, Cádiz, p. 239-253.

Calero, José Ángel (1986) - La muralla romana de Augusta Emerita: Contexto histórico y arqueológico, Cáceres: Universidad de Extremadura, Departamento de Historia Antigua, Memoria de licenciatura.

Casas Genover, Josep y Soler Fuste, Victòria (2006) - Llànties romanes d'Empúries. Materials augustals i altoimperials. Monografies emporitanes, 13, Ampurias.

Deneauve, J. (1969) - Lampes de Carthage, París.

Hidalgo, Luis, Bustamante-Álvarez, Macarena y Pérez, Carmen María (2012) Grafitos sobre cerámica del puticuli de la calle Cabo Verde de Mérida: (España): nuevos datos sobre la cotidianidad Emeritense en el siglo I d. C., Espacio, tiempo y forma, Serie II. Historia Antigua 25, p. 131-172.

JimÉNEZ ÁviLA, Javier (2005) - El Territorio Emeritense en época protohistórica. Antecedentes prerromanos de Augusta Emerita. Augusta Emerita. Territorios, Espacios Imágenes y Gentes en Lusitania Romana. Monografías Emeritenses 8. (T. Nogales ed.) p. 41-66.

Maia, Maria y Maia, Manuel (1997) - Lucernas de Santa Bárbara, Castro Verde.

MÁrquez PÉREZ, J. (1997): Seguimiento arqueológico en la C/ Cesar Lozano, 9, Mérida.

Martín Hernández, Esperanza y RodríGuez Martín, Germán (2008) - Paredes finas de Lusitania y del cuadrante noroccidental. In Bernal, D. y Ribera, Albert, Cerámicas hispanorromanas. Un estado de la cuestión. Cádiz, p. 385-407.

MoRILlo, Ángel (1999) - Lucernas romanas de la región septentrional de la Península Ibérica. Contribución al conocimiento de la implantación romana en Hispania, Monographies instrumentum 8, Montagnac.

Conimbriga, 53 (2014) 145-175 
Palma García, Félix (1997, inéd.): Informe preliminar de los trabajos realizados en el solar sito en la c/ César Lozano n ${ }^{\circ}$ 9, Mérida.

Palma García, Félix (1998) - Intervención arqueológica en el solar de la c/John Lennon, n. 28. Hallazgo de un foso de época almohade en torno a la Alcazaba árabe. Mérida. Excav. Arqueol. 4, p. 161-220.

Palma García, Félix (2004) - Secuencia ocupacional de un espacio extramuros de la Colonia Augusta Emerita. Intervención arqueológica realizada en el solar n. 44 de la calle Augusto, Mérida. Excav. Arqueol. 7, 2001, p. 139-155.

Rodríguez Hidalgo, S. (e.p.): Restos arqueológicos extramuros cercanos a la muralla en la zona norteIntervención arqueológica realizada en la calle César Lozano, no 3 (Mérida), Mérida Excav. Arqueol., 11, 2005.

RodríGUEZ MARTíN, Germán 1996 - Materiales de un alfar emeritense: paredes finas, lucernas, sigillatas y terracotas. Cuadernos Emeritenses, 11. MNAR.

Rodríguez MARTín, Germán (2002) - Lucernas romanas del Museo Nacional de Arte Romano, Monografías Emeritenses, 7, Mérida.

Sánchez Barrero, Pedro Dámaso (2007) - Trabajo desarrollado por el equipo de seguimiento de obras durante el año 2004. Mérida Excav. Arqueol. 10, 2004, p. 409-429.

SÁNCHEZ BARRERo, Gilberto (1997) - Intervención en un solar de la c/ Augusto, no 3. Mérida Excav. Arqueol. 3, p. 128-134.

Szentleleky, T. (1969) - Ancient Lamps, Amsterdam. 


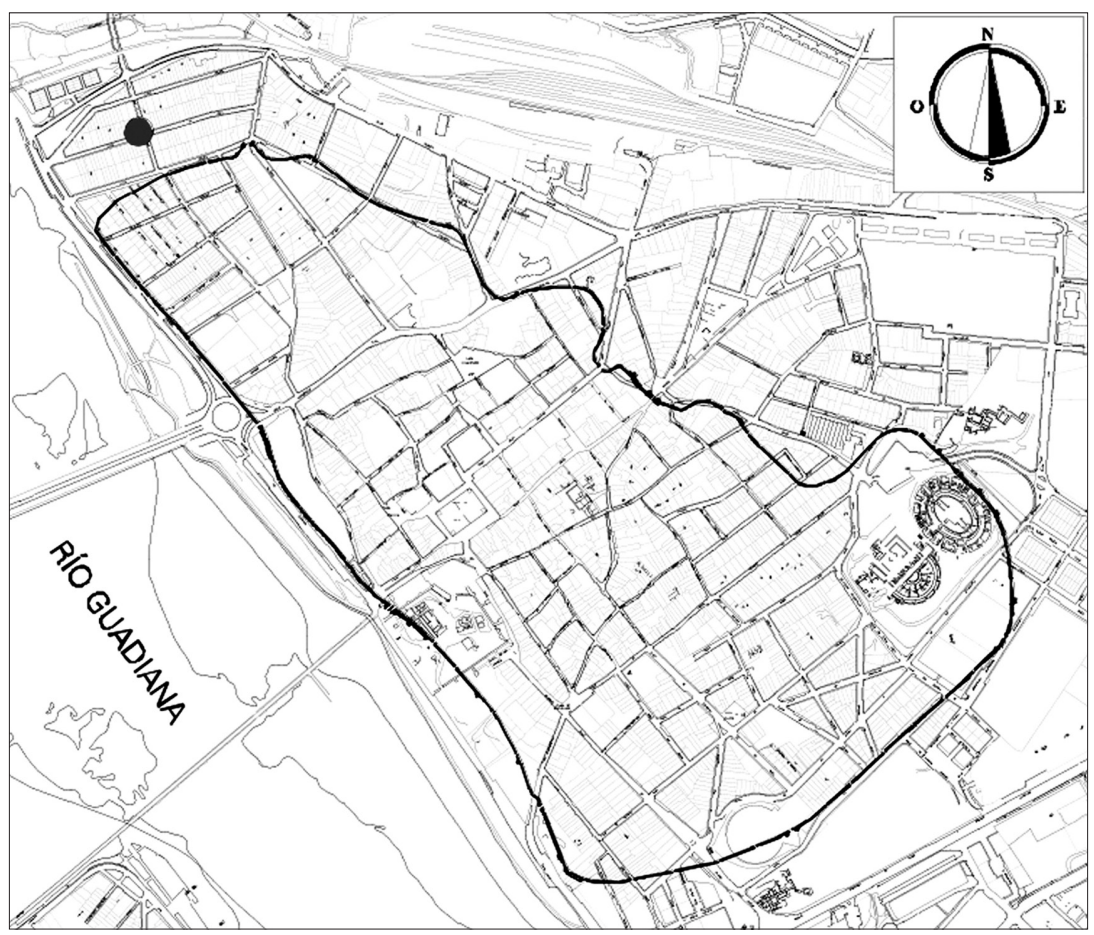

FIG. 1 - Mapa de la ciudad con la ubicación del solar intervenido y los otros complejos alfareros definidos para la producción de lucernas (fuente Consorcio de Mérida). 


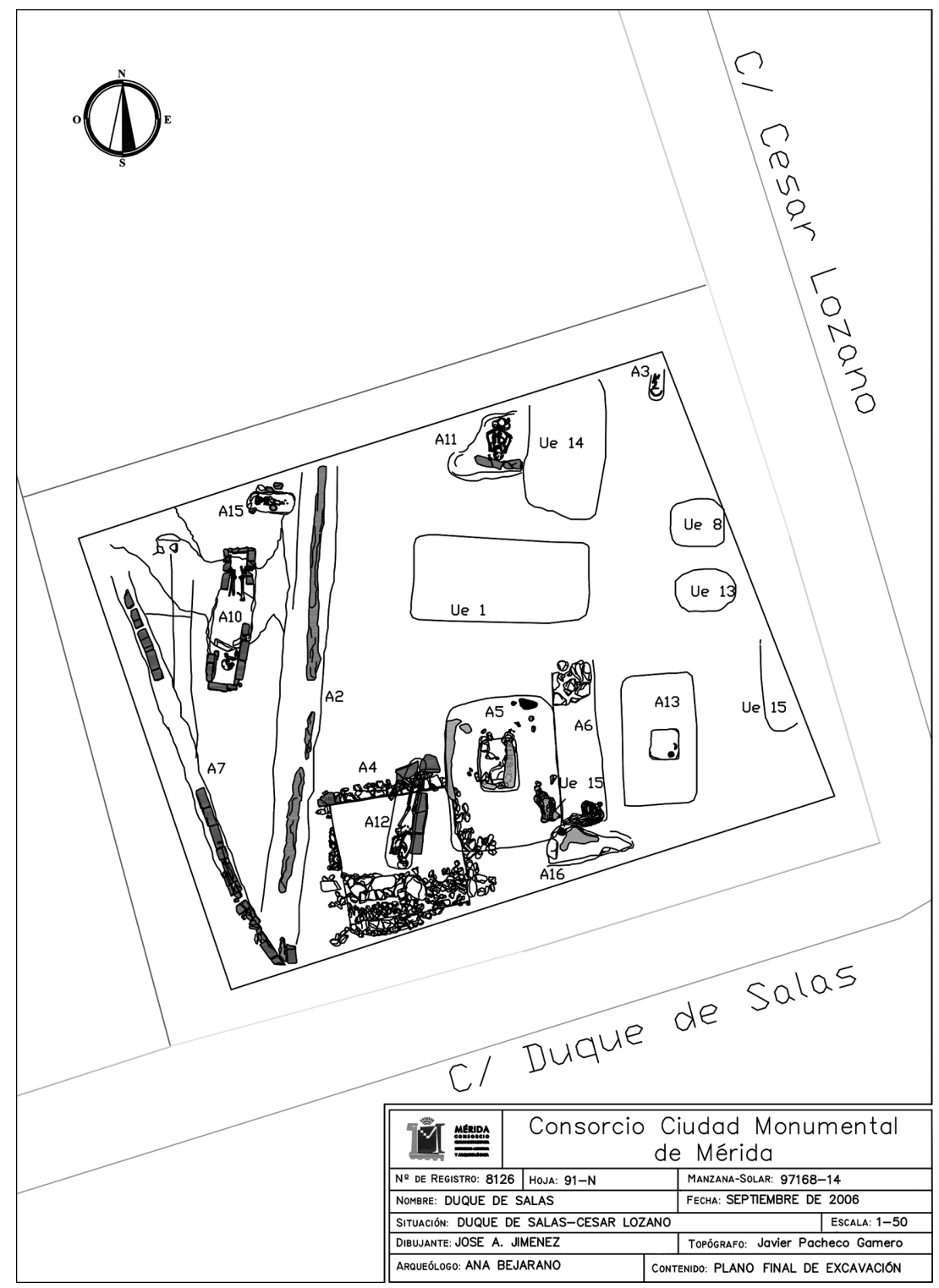

FIg. 2 - Plano del solar así como imagen aérea del solar con las distintas estructuras y subestructuras localizadas (fuente Consorcio de Mérida). 

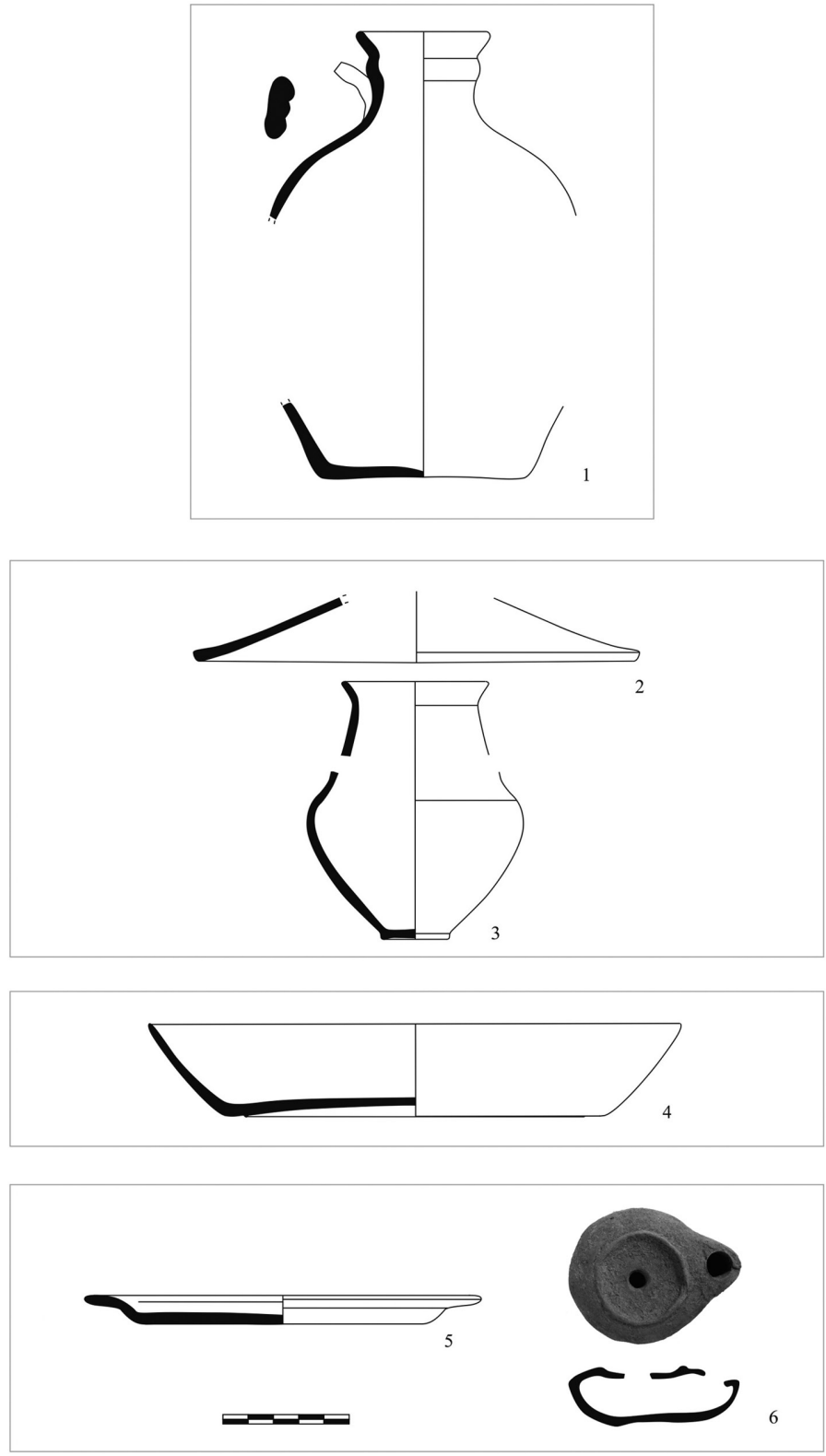

FIG. 3 - Depósitos funerarios localizados durante la fase de necrópolis documentada I. 

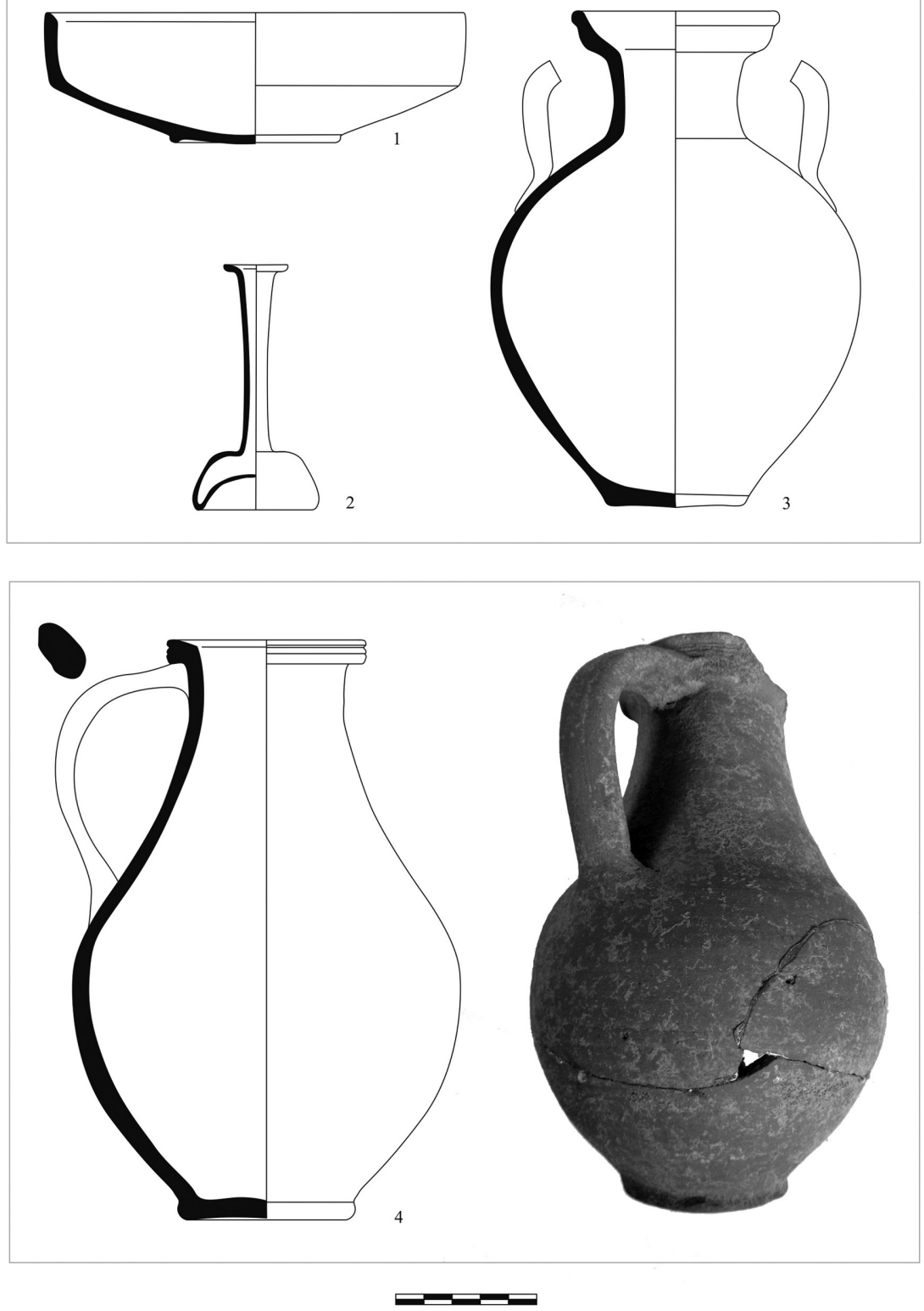

Fig. 4 - Depósitos funerarios localizados

durante la fase de necrópolis documentada II. 

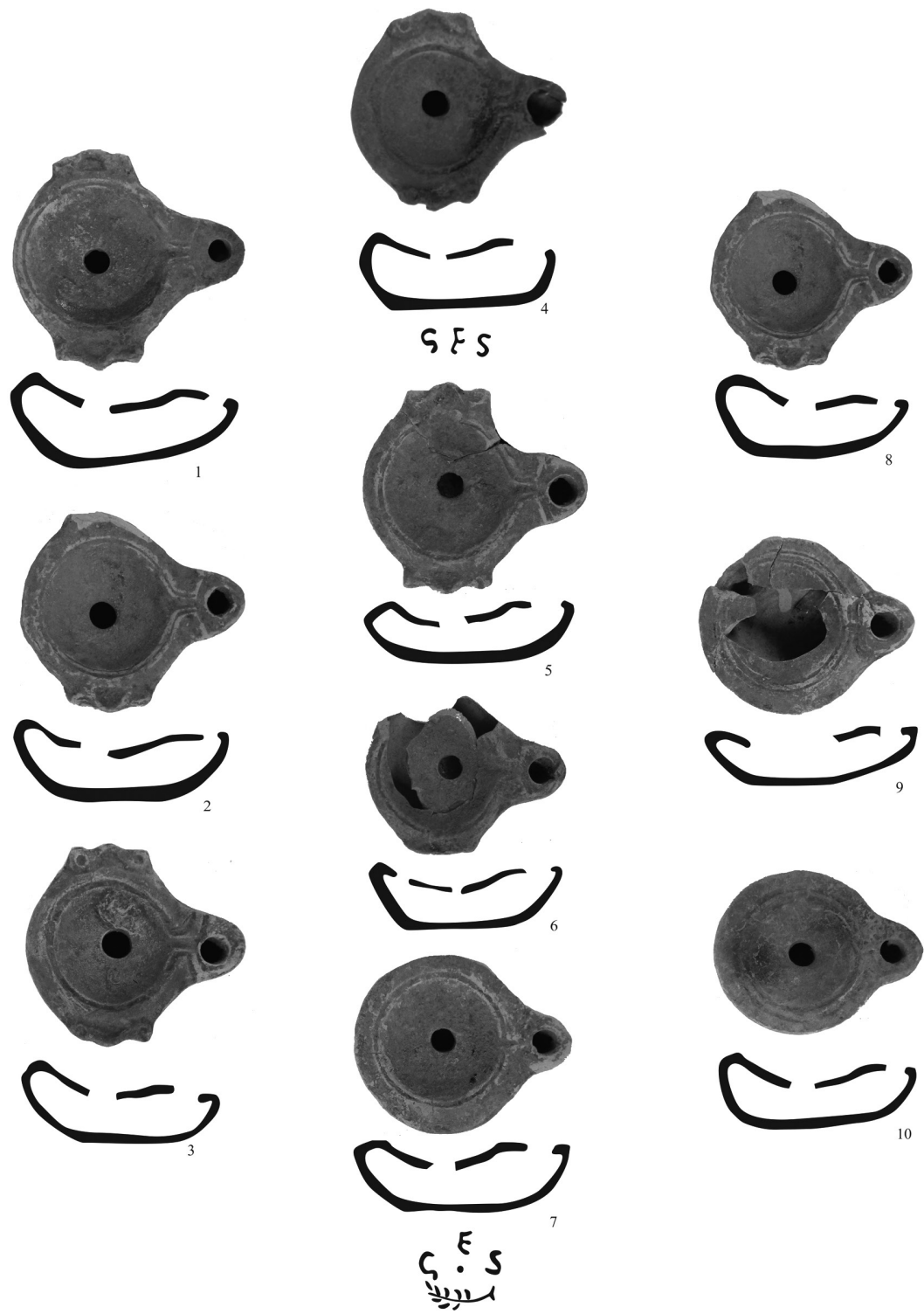

FIG. 5 - Conjunto de lucernas localizados en el interior de la pileta. 

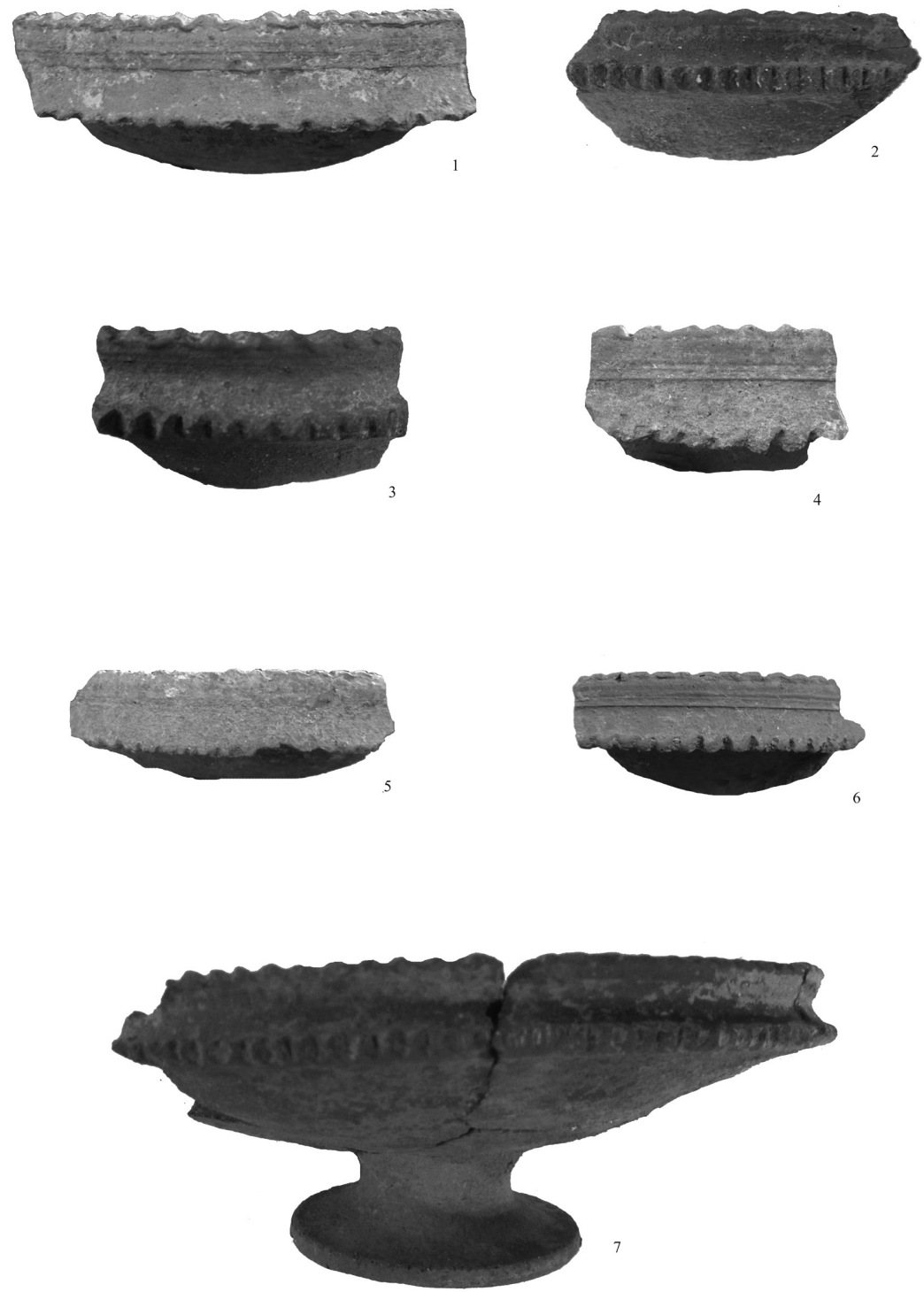

Fig. 6 - Fotografía de algunos bordes de pebeteros así como una sección casi completa donde observamos su termoalteración. 

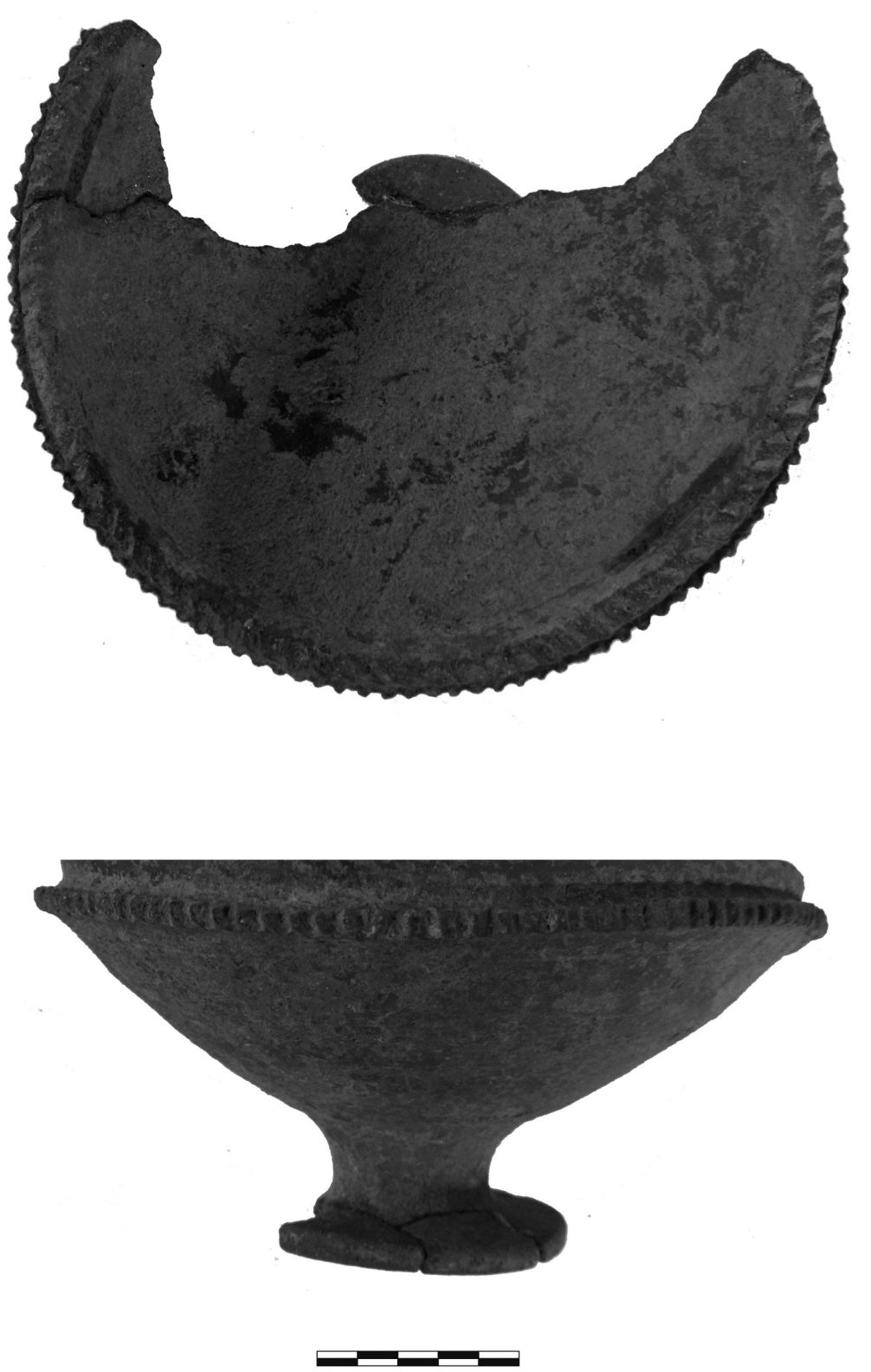

FIG. 7 - Imagen de pebetero con deformaciones en su factura final. 

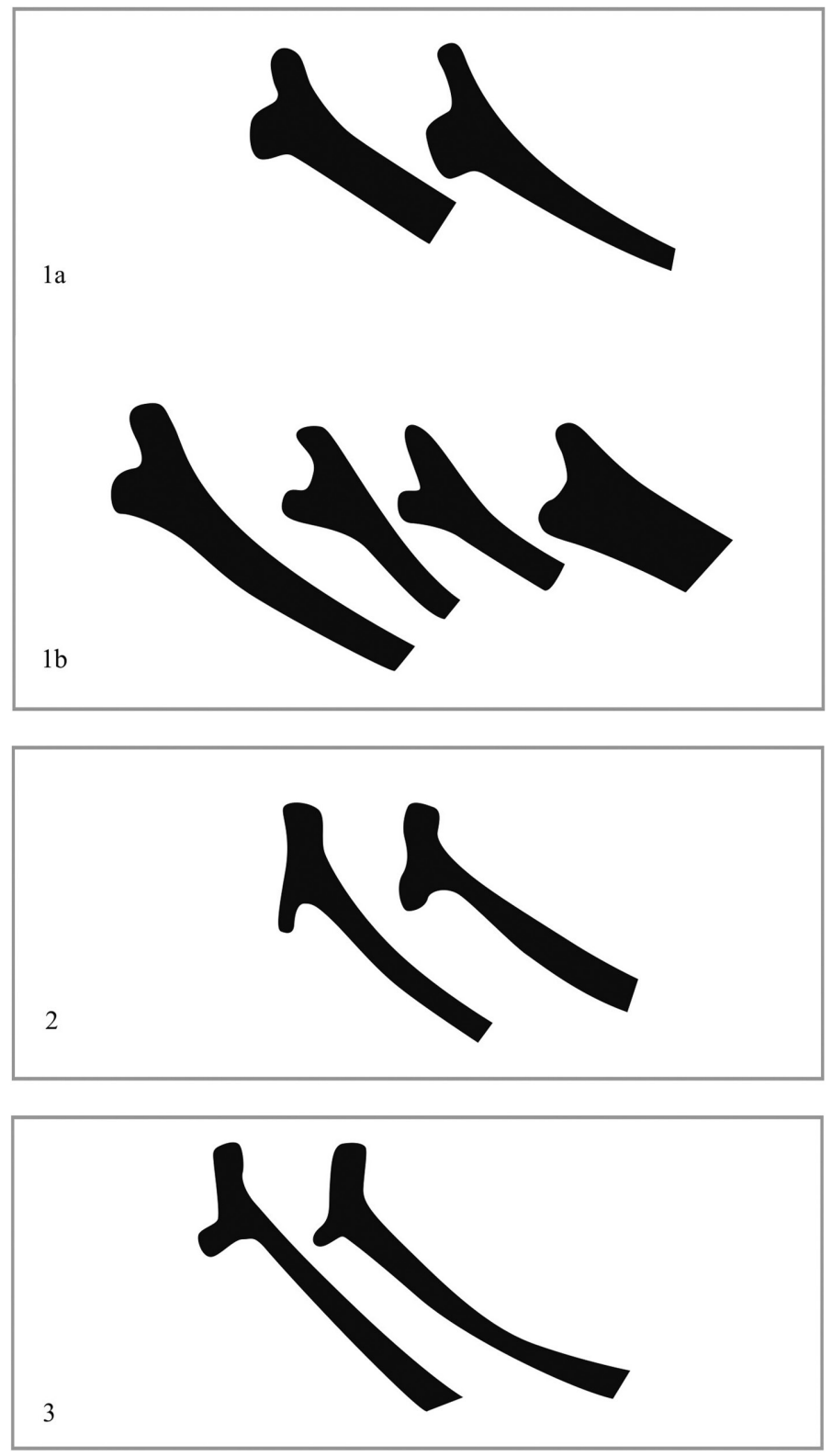

FIG. 8 - Tipología de bordes de pebetero perfilada a partir de los ejemplares localizados. 


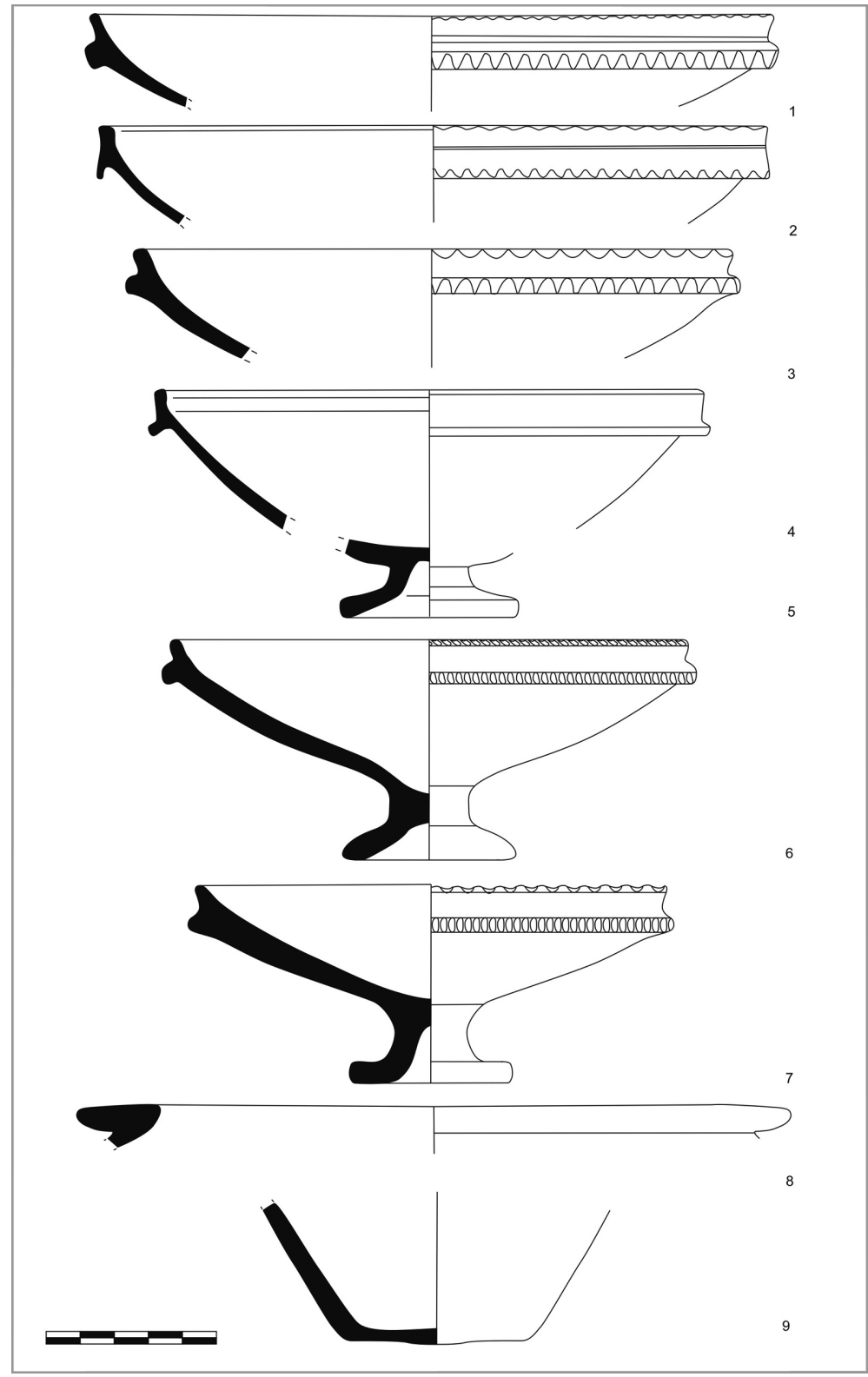

FIG. 9 - Ejemplos de pebeteros (n. $\left.{ }^{o s} 1-7\right)$

y cerámicas comunes localizadas $\left(n{ }^{o s} 8-9\right)$. 

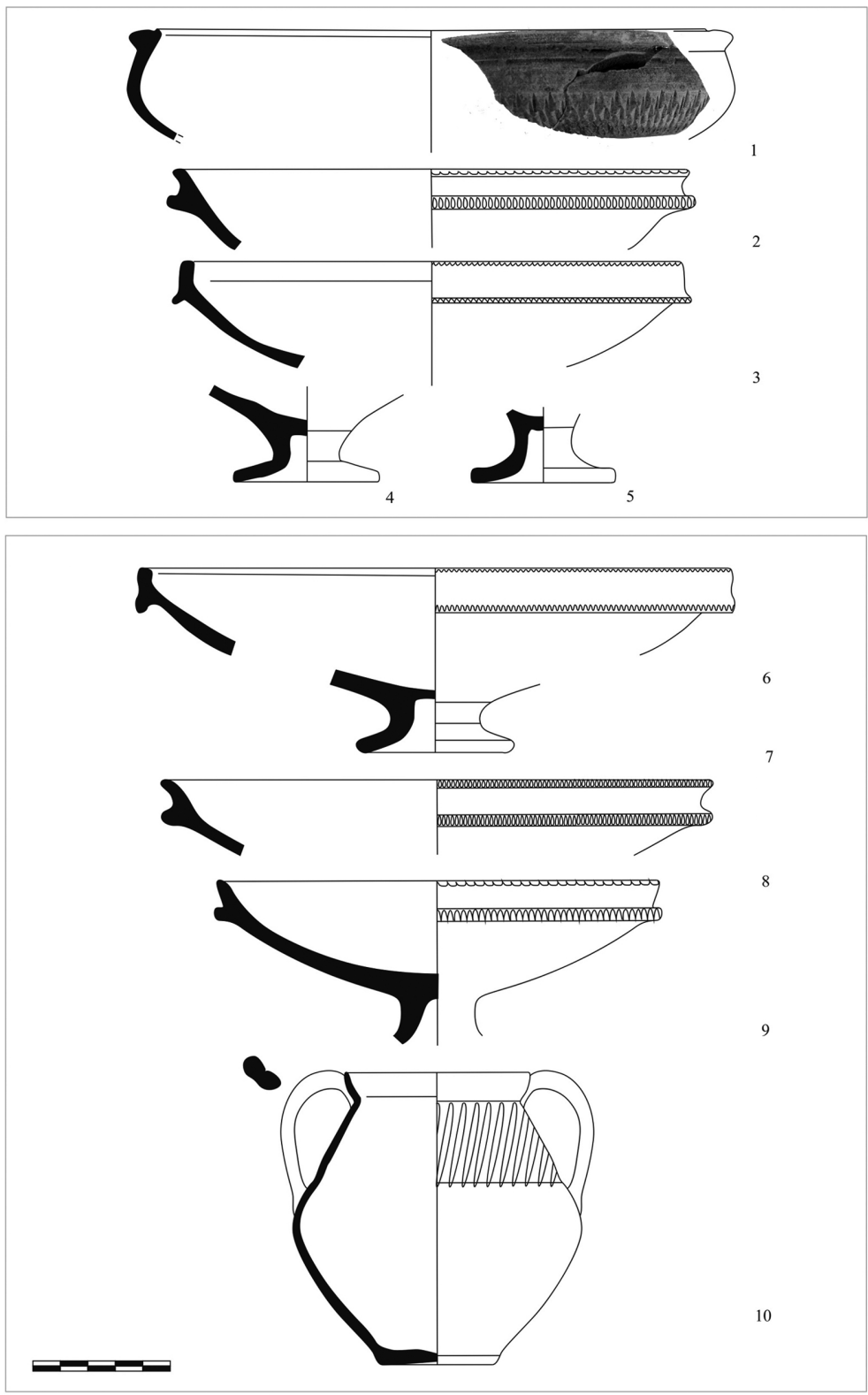

FIG. 10 - Ejemplos de pebeteros $\left(n .^{o s} 2-9\right)$, paredes finas emeritenses $\left(n .^{\circ} 1\right)$ $y$ comunes locales $\left(n{ }^{\circ} 10\right)$ 